Jurnal Ayurveda Medistra ISSN. 2656-5609
Volume 2 Issue 1 | 2020 | pages:8-15 Jurnal
Ayurveda Medistra Avalaible online at
http://ojs.stikesmedistra-indonesia.ac.id/

\title{
Pengaruh Edukasi Diet Diabetes Dan Senam Kaki Terhadap Kadar Gula Darah Pada Penderita Diabetes Melitus Di Puskesmas Padurenan RT 002 / RW 10 Bekasi 2019
}

\author{
Ernauli Meliyana ${ }^{1}$, Mila Nofiana ${ }^{2}$
}

\author{
1Program Studi Keperawatan (S1) STIKes Medistra Indonesia, cellohtst@yahoo.com, 081318174695 \\ 2 Program Studi Keperawatan (S1) STIKes Medistra Indonesia, mil.milanoviana@gmail.com, 082112724811
}

\begin{abstract}
Abstrak
Diabetes Melitus merupakan suatu penyakit kronis yang terjadi ketika pankreas tidak mampu menghasilkan insulin yang cukup. Penyakit Diabetes Melitus di Indonesia akan terus mengalami kenaikan seiring perubahan gaya hidup yang kurang sehat, terutama pola makan yang tidak sehat dan aktifitas fisik yang kurang. Edukasi diikuti dengan aktifitas fisik diperlukan untuk memberikan manfaat bagi tubuh karena dengan cara berolahraga dapat menurunkan gula darah. Aktivitas fisik yang dianjurkan berupa senam, dimana salah satunya adalah senam kaki diabetes yang merupakan kegiatan atau latihan yang dilakukan oleh pasien diabetes melitus dalam rangka mencegah dan meminimalisir terjadinya luka, membantu memperlancar peredaran darah bagian kaki. Mengetahui Pengaruh edukasi diet diabetes dan aktivitas senam kaki diabetes terhadap kadar gula darah pada penderita Diabetes Melitus di Puskesmas Padurenan RT002/RW10 Bekasi 2019. Desain yang digunakan dalam penelitian ini adalah "Quasi Exsperiment Time Series Design" dengan intervensi edukasi diet diabetes dan senam kaki diabetes. Jumlah sampel penelitian ini 12 responden.Uji statistik menggunakan Paired T-Test. Ada pengaruh edukasi diet diabetes terhadap tingkat pengetahuan dengan nilai $p$ value sebesar 0.000 ( $p$ value $<$ $0.05)$, dan ada pengaruh senam kaki diabetes terhadap kadar gula darah dengan nilai $p$ value sebesar 0.002 ( $p$ value< 0.05 ). Edukasi diet diabetes dan senam kaki diabetes berpengaruh terhadap tingkat pengetahuan dan kadar gula darah pada penderita diabetes melitus di Puskesmas Padurenan RT 002 / RW 10 Bekasi.
\end{abstract}

Kata kunci: Edukasi, diabetes, senam kaki.

\section{Abstract}

The Diabetes Melitus is a cronic disease occurred in pancreatic when it is could not produce enough insulin. Diabetes Melitus in Indonesia will continue to increase with changes in lifestyle that unhealthy lifestyle, especially unhealthy eating patterns and lack of physical activity. Education to follow with physical activity needed to provide benefits to the body because by exercising can reduse blood sugar. Physical activity that is recommended by gymnastics, where it called legs exercise of Diabetes Melitus is an activity or training carried out by diabetes melitus patients for prevent and minimizer the injury and help smoothen circulation for the legs. Knowing influence of diabetes diet education and diabetes legs exercise for control the level of blood sugar in diabetes melitus patients brand of health service (puskesmas) names Padurenan. The designed used in this research is "Quasi Exsperiment Time Series Design" with intervention of diabetes diet education and diabetes legs exercise. The sample size of this research was 12 respondents. Statistikal test using Paired T-Test. There is influence of diabetes diet on knowledge level with value $p$ value is 0.000 ( $p$ value $<0.05$ ). The analisis result showed that was a influencing legs exercise to the blood sugar level where is the $p$ value les than $<0.005$ ( $p$ value 0.002). The education of Diabetes diet and legs exercise were influencing to the knowledge of diabetes and blood sugar level of patients in the brand of health service (puskesmas) names Padurenan RT 002/RW 10 Bekasi. 
Keywords: education, diabetic, legs exercise.

\section{PENDAHULUAN}

Diabetes Melitus adalah defisiensi relative atau absolut dari hormon insulin. Insulin merupakan satu-satunya hormon yang dapat menurunkan kadar glukosa dalam darah ${ }^{1}$. Sejak dahulu penyakit ini merupakan salah satu penyakit yang sering menjangkit lansia dengan kisaran usia diatas 35 tahun. Dengan perubahan gaya hidup penduduk modern, penyakit Diabetes Melitus mengalami pergeseran dimana usia penderita bahkan sudah mengenai usia dewasa awal yaitu 20 tahun, tentu data tersebut patut menjadi perhatian saat ini.

Gaya hidup meliputi diet Diabetes dan aktifitas sehari-hari yang kurang baik sangat mempengaruhi terhadap peningkatan kadar gula darah, maka dari itu diet Diabetes yang baik merupakan kunci utama dalam penanganan pasien Diabetes Melitus (DM). Pemilihan makan yang tepat dapat membantu pengontrolan gula darah. Konsumsi makanan tinggi serat dan indeks glikemik rendah dapat membantu mengontrol kadar glukosa darah pasien Diabetes Melitu. Diet Diabetes merupakan asupan makanan yang memberikan berbagai macam jumlah, jadwal dan jenis makanan yang didapatkan seseorang. Pengaturan diet Diabetes yang tidak tepat seperti yang dianjurkan 3J (Jadwal, Jumlah dan Jenis) dapat mengakibatkan peningkatan kadar gula darah ${ }^{3}$.

Aktivitas atau olahraga yang kurang dapat mempengaruhi peningkatan kadar gula darah. Latihan jasmani merupakan upaya awal dalam mencegah, mengontrol dan mengatasi Diabetes.Pentingnya dilakukan latihan jasmani sepertiSenam kaki diebetes dapat dilakukan untuk menghindari terjadinya gangren dan amputasi.Senam kaki diebetes juga dapat membantu memperbaiki sirkulasi darah dan memperkuat otot-otot kecil kaki dan mencegah terjadinya kelainan bentuk kaki.Selain itu dapat meningkatkan kekuatan otot betis, otot paha, dan juga mengatasi keterbatasan gerak sendi ${ }^{3}$.

Penyakit Diabetes Melitus di Indonesia akan terus mengalami kenaikan seiring perubahan gaya hidup. Data Federasi Internasional Diabetes didunia (International Diabetes Federation) menunjukan bahwa 1 dari 12 orang di dunia menderita penyakit Diabetes Melitus, 1 dari 2 orang penderita Diabetes Melitus tidak mengetahui bahwa dirinya menderita Diabetes Melitus, biasanya penderita baru akan mengetahui kondisinya bila penyakit sudah berjalan dengan komplikasi yang sangat jelas terlihat sehingga melakukan pengobatan dan pemeriksaan di rumah sakit ${ }^{2}$. DiabetesMelitus (DM) adalah salah satu jenis penyakit degeneratif yang mengalami peningkatan setiap tahun di negara-negara seluruh dunia. Tingkat prevalensi global penderita Diabetes Melitus pada tahun 2014 sebesar $8,3 \%$ dari keseluruhan penduduk di dunia dan mengalami peningkatan pada tahun 2014 menjadi 387 juta kasus. Indonesia merupakan negara menempati urutan ke 7 dengan penderita Diabetes Melitussejumlah 8,5 juta penderita setelah Cina, India, Amerika Serikat, Brazil, Rusia dan Mexico 4 .

Indonesia merupakan salah satu negara berkembang di dunia yang penduduknya banyak menderita DiabetesMelitus, dengan bertambahnya jumlah penduduk diikuti dengan peningkatan kualitas pelayanan kesehatan maka angka harapan hidup di Indonesia juga semakin meningkat, akibatnya penduduk lansia semakin banyak sehingga bertambahnya jumlah penderita DiabetesMelitus tidak dapat dihindari ${ }^{3}$. Jumlah penderita Diabetes Melitus di wilayah perkotaan lebih tinggi dibandingkan dengan wilayah pedesaan. Prevalensi Diabetes Melitus justru cenderung lebih tinggi pada masyarakat dengan tingkat pendidikan tinggi ${ }^{5}$. Jumlah penderita Diabetes Melitus di Indonesia pada tahun 2014 adalah 9,1 juta jiwa. Diabetes Melitus yang tidak terdiagnosis berjumlah 4,8 juta, penderita yang meninggal akibat Diabetes Melitus berjumlah 175.836 jiwa, diperkirakan jumlah penduduk Indonesia yang menderita Diabetes Melitus di tahun 2035 mencapai 14,1 juta 2 .

Berdasarkan studi pendahuluan yang dilakukan peneliti pada bulan Mei 2019 di Puskesmas Padurenan, didapatkan hasil penderita Diabetes Melitus pada tahun 2017 berjumlah 425 pasien dan ada kenaikan pada tahun 2018 berjumlah 501 pasien. Adapun tujuan dari penelitian ini adalah untuk mengetahui pengaruh edukasi diet Diabetes dan aktivitas senam kaki Diabetes terhadap kadar gula darah pada penderita Diabetes Melitus di Puskesmas Padurenan RT002/RW10 Bekasi 2019.

\section{METODE PENELITIAN}


Populasi dalam penelitian ini adalah seluruh penderita DiabetesMelitus di Puskesmas Padurenan RT 002/ RW 10 Bekasi. Sampel dalam penelitian ini adalah penderita Diabetes Melitus di Puskesmas Padurenan sebanyak 12 responden. Teknik pengambilan sampel penelitian ini menggunakan jenis Non Probability Sampling yaitu teknik yang tidak memberikan kesempatan yang sama bagi anggota populasi untuk dipilih menjadi sampel. Pada penelitian ini menggunakan jenis penelitian Kuantitatif, dalam desain penelitian Ekperimental dengan pendekatan Time Series Design. Jenis kuantitatif adalah manipulasi atau intervensi yang dilakukan oleh peneliti kepada subyek peneliti.

Rancangan penelitian Quasi Ekperimental atau percobaan adalah kegiatan percobaan (experiment), yang bertujuan untuk mengetahui suatu gejala atau pengaruh yang timbul, sebagai akibat dari adanya perlakuan tertentu. Dengan pendekatan Time Series Design.

Selain kuesioner instrumen yang digunakan dalam penelitian ini adalah menggunakan glukometer sebagai alat ukur kadar gula darah pada penderita DiabetesMelitus.

Analisa data dalam penelitian ini menggunakan analisa univariat bertujuan untuk mendeskripsikan karakteristik setiap variabel. Analisa Bivariat dalam penelitian ini menggunakan Uji Paired T-test untuk mengetahui beda mean nilai variabel independen antara 2 pengukuran (pre dan post test) yang dibentuk oleh variabel dependen.Sebelum dilakukan uji Paired $T$ Test maka dilakukan terlebih dahulu Uji Normalitas sebagai persyaratan Uji Paired $T$ Test.

\section{Metode Pengumpulan Data}

Rancangan ini seperti rancangan pre testpost test, dengan keuntungan melakukan observasi (pengukuran yang berulang) sebelum dan sesudah perlakuan ${ }^{6}$. Pada penelitian ini menggunakan cara pretest (pengamatan awal) terlebih dahulu sebelum diberikan intervensi tentang edukasi kesehatan diet Diabetes dan aktivitas senam kaki Diabetes terhadap kadar gula darah pada penderita Diabetes Melitus, setelah itu diberikan intervensi, kemudian dilakukan posttest (pengamatan akhir). Berdasarkan uraian diatas, maka dapat dirumuskan desain penelitian.

Sesuai karakteristik inklusi dan eksklusi yang telah di tentukan dalam penelitian ini Penderita Diabetes Melitus yang dapat berkomunikasi secara verbal, Penderita DiabetesMelitus yang dapat berinteraksi sosial, Penderita DiabetesMelitus yang tidak memiliki gangguan fisik apapun, Penderita DiabetesMelitus yang dapat membaca, Penderita DiabetesMelitus yang bersedia menjadi responden. Instrumen pengumpulan data yang digunakan dalam penelitian adalah menggunakan lembar kuesioner.Dalam pengumpulan data ini, responden diberi kebebasaan untuk mengisi dengan jawaban yang sesuai menurut responden dan kuesioner berbentuk pilihan, dimana jawaban telah disediakan sehingga responden tinggal memilih jawabannya.

\section{HASIL DAN PEMBAHASAN}

Tabel 1 : Pengetahuan Tentang Diet Diabetes Sebelum Dilakukan Edukasi Kesehatan Pada Penderita Diabetes di Puskesmas Padurenan RT002 / RW10 Bekasi

\begin{tabular}{ccc}
\hline Kategori & Frekuensi (f) & $\begin{array}{c}\text { Persentase } \\
(\%)\end{array}$ \\
\hline Baik & 0 & 0 \\
Cukup & 4 & 33,3 \\
Kurang & 8 & 66,7 \\
\hline Total & 12 & 100 \\
\hline Sumber : hasil
\end{tabular}

komputerisasi Tim, Juli 2019)

Tabel 1 diatas dapat diketahui bahwa pengetahuan responden tentang diet Diabetes sebelum dilakukan edukasi kesehatan, dari 12 responden 4 responden $(33,3 \%)$ berada dalam kategori cukup, 8 responden $(66,7 \%)$ berada dalam kategori kurang.

Diet Diabetes adalah penderita Diabetes harus dapat mengendalikan dalam hal jadwal makan, jumlah makanan yang dimakan dan jenis makanan yang dikonsumsi. Pengaturan makan ini bertujuan untuk mempertahankan kadar gula darah sampai normal/mendekati normal, mempertahankan berat badan ideal, mencegah hipoglikemi dan mengurangi komplikasi. $^{2}$

Hasil analisa peneliti yang dilakukan di Puskesmas Padurenan RT 002 / RW 10 Bekasi adalah banyak penderita Diabetes yang beranggapan bahwa bila terkena Diabetes, mereka akan selalu berhadapan dengan makanan yang tawar, hambar, atau tidak enak 
sama sekali, karena hal tesebut membuat penderita Diabetes menjadi tidak mau menjaga pola makannya, karena tingkat pengetahuan yang rendah tentang diet Diabetes akan dapat mempengaruhi pola makan yang salah yang akhirnya akan mengakibatkan kenaikan kadar glukosa darah.

Hal ini sejalan dengan hasil penelitian yang dilakukan oleh Ayu Putri Rahayu (2012) sebelum diberikan edukasi kesehatan responden sebanyak 42 orang, 45,2\% dalam kategori kurang, 54,8\% responden yang termasuk dalam kategori pengetahuan cukup.

Tabel 2 : Pengetahuan Tentang Diet Diabetes Sesudah Dilakukan Edukasi Kesehatan Pada Penderita Diabetes di Puskesmas Padurenan RT002 / RW10 Bekasi

\begin{tabular}{ccc}
\hline Kategori & Frekuensi (f) & Persentase (\%) \\
\hline Baik & 4 & 33,3 \\
Cukup & 8 & 66,7 \\
Kurang & 0 & 0 \\
\hline Total & 12 & 100
\end{tabular}

(Sumber : hasil pengolahan data dengan cara komputerisasi Tim, Juli 2019)

Hasil penelitian diketahui bahwa tingkat pengetahuan sesudah diberikan edukasi kesehatan tentang diet Diabetes dari 12 responden ada 4 responden $(33,3 \%)$, berada dalam kategori baik, 8 responden $(66,7 \%)$ berada dalam kategori cukup.

Banyak orang beranggapan bahwa bila terkena Diabetes, mereka akan selalu berhadapan dengan makanan yang tawar, hambar, atau tidak enak sama sekali. Mereka menjadi cemas, panik, bahkan takut menghadapi kenyataan bahwa mereka telah mengidap Diabetes beranggapan tidak bisa makan apa-apa lagi. ${ }^{3}$

Sebenarnya penderita Diabetes Melitus boleh menikmati semua makanan yang di sukai.Hanya saja, harus disesuaikan dengan keadaan Diabetes.Kurangi jumlah makanan yang mengandung gula atau karbohidrat. Ubah cara penyajiannya dan atur waktu makannya. Mengatur makanan yang sehat bukan berarti dilarang ini atau dilarang itu, melainkan menyesuaikan kalori yang masuk dengan kebutuhan tubuh? ${ }^{7}$.

Hasil analisa peneliti yang dilakukan di Puskesmas Padurenan RT 002 / RW 10 Bekasi adalah meningkatnya pengetahuan tentang diet Diabetes pada penderita DiabetesMelitus dikarenakan adanya edukasi kesehatan yaitu penerapan pendidikan di dalam bidang kesehatan untuk memberikan atau meningkatkan pengetahuan, sikap, dan praktek baik individu, kelompok atau masyarakat dalam memelihara dan meningkatkan kesehatan mereka sendiri

Hal ini sejalan dengan hasil penelitian yang dilakukan oleh Ayu Putri Rahayu (2012) sebelum diberikan edukasi kesehatan sebanyak 42responden, 47,7\% sampel masuk kedalam kategori pengetahuan cukup sedangkan $2,4 \%$ sampel dikategorikan pengetahuan kurang.

Tabel 3 : Kadar Gula Darah Sebelum Diberikan Senam Kaki Pada Penderita Diabetes di Puskesmas Padurenan RT002 / RW10 Bekasi

\begin{tabular}{ccc}
\hline $\begin{array}{c}\text { Kadar Gula Darah } \\
\text { (mg/dl) }\end{array}$ & $\begin{array}{c}\text { Frekuensi } \\
\mathbf{( f )}\end{array}$ & Persentase\% \\
\hline Tinggi $(160-240 \mathrm{mg} / \mathrm{dl})$ & 7 & 58,3 \\
Sangat Tinggi $(240-$ & 5 & 41,7 \\
$300 \mathrm{mg} / \mathrm{dl})$ & 0 & 0 \\
$\begin{array}{c}\text { Berbahaya }(>300 \\
\mathrm{mg} / \mathrm{dl})\end{array}$ & & \\
\hline Total & 12 & 100 \\
\hline $\begin{array}{l}\text { (Sumber : hasil pengolahan } \\
\text { komputerisasi Tim, Juli 2019) }\end{array}$ & &
\end{tabular}

Berdasarkan hasil penelitian yang dilakukan pada 12 responden, menunjukan bahwa kadar gula darah sebelum dilakukan senam kaki diabetes pada penderita Diabetes Melitus di Puskesmas Padurenan RT 002 / RW 10 Bekasi. Terdapat 7 responden (58,3\%) berada dalam kategori tinggi dengan rentang kadar gula darah dari $160-240 \mathrm{mg} / \mathrm{dl}$. dan 5 responden $(41,7 \%)$ berada dalam kategori sangat tinggi dengan rentang kadar gula darah dari 240 - $300 \mathrm{mg} / \mathrm{dl}$.

Glukosa darah adalah gula yang terdapat dalam darah yang berasal dari karbohidrat dalam makanan dan disimpan dalam bentuk glikogen di dalam hati dan otot rangka. ${ }^{2}$ Karena itu sebaiknya penderita Diabetes Melitus melaksanakan 4 pilar pengolahan Diabetes Melitus salah satunya adalah latihan jasmani. Latihan jasmani secara teratur dapat menurunkan kadar gula darah. Latihan jasmani selain untuk menjaga kebugaran juga dapat menurunkan berat badan dan memperbaiki sensitivitas insulin, sehingga akan memperbaiki kendali glukosa darah. Salah satu latihan jasmani adalah senam kaki Diabetes yaitu kegiatan atau latihan yang dilakukan oleh pasien DiabetesMelitus untuk mencegah terjadinya luka dan membantu memperlancar peredaran darah bagian kaki. ${ }^{2}$

Hasil analisa peneliti yang dilakukan di Puskesmas Padurenan RT 002 / RW 10 Bekasi 
adalah kadar gula darah yang tinggi pada penderita Diabetes Melitus disebabkan oleh pola makan yang tidak baik dan kurangnya aktivitas fisik, mereka beranggapan bahwa melakukan senam kaki adalah kegiatan yang tidak ada manfaatnya ditambah lagi dengan keluhan dalam keterbatasan waktu yang mereka miliki. Keadaan seperti ini membuat penderita DiabetesMelitus sulit untuk mempertahankan kadar gula darah sampai normal/mendekati normal.

$\mathrm{Hal}$ ini sejalan dengan penelitian Graceistin Ruben (2016) sebelum dilakukan senam kaki sebanyak 56 responden (100\%) kadar gula darahnya $\geq 200 \mathrm{mg} / \mathrm{dl}$. Dan hal ini juga sejalan dengan penelitian Gusti Rizal Rusli (2015), sebelum dilakukan senam kaki dari 20 responden, terdapat 14 responden kadar gula darahnya pada interval $240-249$ $\mathrm{mg} / \mathrm{dl}$. Kadar gula darah yang relative tinggi ini dipengaruhi oleh beberapa faktor diantaranya pola diet dan aktivitas sesuai teori yang dikemukakan oleh Tandra (2008)

Tabel .4 Kadar Gula Darah Sesudah Diberikan Senam Kaki Pada Penderita Diabetes di Puskesmas Padurenan RT002 / RW10 Bekasi

\begin{tabular}{ccc}
\hline $\begin{array}{c}\text { Kadar Gula Darah } \\
(\mathbf{m g} / \mathbf{d l})\end{array}$ & Frekuensi & $\begin{array}{c}\text { Persen } \\
\text { tase } \%\end{array}$ \\
\hline Tinggi $(160-240 \mathrm{mg} / \mathrm{dl})$ & 12 & 100 \\
Sangat Tinggi $(240-300$ & 0 & 0 \\
$\mathrm{mg} / \mathrm{dl})$ & 0 & 0 \\
Berbahaya $(>300 \mathrm{mg} / \mathrm{dl})$ & & 100 \\
\hline Total & 12 & \\
$\begin{array}{c}\text { (Sumber : hasil pengolahan } \\
\text { komputerisasi Tim, Juli 2019) }\end{array}$ & data dengan cara &
\end{tabular}

Berdasarkan hasil penelitian yang dilakukan pada 12 responden, menunjukan bahwa kadar gula darah sesudah dilakukan senam kaki diabetes pada penderita Diabetes Melitus di Puskesmas Padurenan RT 002 / RW 10 Bekasi, dari 12 responden (100\%) berada dalam kategori tinggi dengan rentang kadar gula darah dari $160-240 \mathrm{mg} / \mathrm{dl}$.

Hasil analisa peneliti yang dilakukan di Puskesmas Padurenan RT 002 / RW 10 Bekasi menurunya kadar gula darah pada penderita DiabetesMelitusdari interval sangat tinggi ke tinggi. hal tersebut dikarenakan responden melakukan senam kaki diabetes dengan baik dan benar serta dilakukan secara berkelanjutan sehingga sirkulasi dalam darah meningkat dan terjadi penurunan kadar gula darah pada penderita Diabetes Melitus. pengaruh senam kaki diabetes terhadap perubahan kadar gula darah yaitu pada otot otot yang bergerak aktif dapat meningkatkan kontraksi sehingga permeabilitas membran sel terhadap peningkatan glukosa, resistensi insulin berkurang dan sensivitas insulin meningkat. Sehingga sirkulasi dalam darah meningkat dan terjadi penurunan kadar gula darah pada penderita DiabetesMelitus.

$\mathrm{Hal}$ ini sejalan dengan penelitian Graceistin Ruben (2016) sebelum dilakukan senam kaki sebanyak 56 responden, 42 responden $(75 \%)$ kadar gula darahnya $150-$ $199 \mathrm{mg} / \mathrm{dl}, 14$ responden (25\%) kadar gula darahnya $\geq 200 \mathrm{mg} / \mathrm{dl}$. Hal ini menggambarkan bahwa ke-42 responden yang melakukan senam kaki dengan baik dan benar secara teratur relatif memiliki kadar gula darah $\leq 200$ $\mathrm{mg} / \mathrm{dl}$. Nilai kadar gula darah yang lebih rendah atau turun ini menggambarkan terjadinya perbaikan nilai kadar gula darah setelah melakukan senam kaki.

Selain itu hal ini juga sejalan dengan penelitian Gusti Rizal Rusli (2015) dari 20 responden, terdapat 14 responden kadar gula darahnya pada interval $200-209 \mathrm{mg} / \mathrm{dl}$.

Tabel .5 Uji Normalitas Data Tingkat Pengetahuan sebelum dan Sesudah Dilakukan Edukasi Kesehatan

\begin{tabular}{cccc}
\hline Variabel & $\begin{array}{c}\text { Pengukura } \\
\mathrm{n}\end{array}$ & $\mathrm{P}$ Value & $\begin{array}{l}\text { Frekuen } \\
\text { si }\end{array}$ \\
\hline Tingkat & Sebelum & 0,303 & 12 \\
\cline { 2 - 4 } $\begin{array}{c}\text { Pengetahu } \\
\text { an }\end{array}$ & Sesudah & 0,130 & 12 \\
\hline
\end{tabular}

(Sumber : hasil pengolahan data dengan cara komputerisasi Tim, Juli 2019)

Berdasarkan hasil penelitian yang dilakukan pada 12 responden, menunjukan bahwa nilai mean tingkat pengetahuan sebelum diberikan edukasi diet Diabetes pada penderita DiabetesMelitus adalah 12.08 dengan standar deviasi 2.875 mengalami kenaikan nilai mean sesudah dilakukan edukasi diet Diabetesadalah 17.42 dengan standar deviasi 2.875.Dalam penelitian ini terdapat perbedaan nilai mean sebelum dan sesudah dilakukan edukasi kesehatan dengan selisih 5.83dapat diartikan bahwa ada pengaruh sebelum dan sesudah dilakukan edukasi kesehatan hasil analisa dengan menggunakan paired sampel $t$ test dengan hasil $p$ value sebesar $(0.000)$ sehingga $p$ value $(0.000)<$ alpha $(0,05)$. Dapat disimpulkan bahwa hasi uji hipotesis dinyatakan $\mathrm{H}_{0}$ ditolak, maka ada pengaruh setelah dilakukan edukasi kesehatan tentang diet Diabetes. 
Metode edukasi kesehatan yang digunakan dalam penelitian ini adalah metode edukasi kelompok dengan bentuk ceramah.Media edukasi kesehatan yang digunakan adalah lembar balik dan leaflet. Tujuan memberikan edukasi kesehatan adalah penerapan pendidikan di dalam bidang kesehatan untuk memberikan atau meningkatkan pengetahuan, sikap, dan praktek baik individu, kelompok atau masyarakat dalam memelihara dan meningkatkan kesehatan mereka sendiri, khusunya bagi penderita DiabetesMelitus agar dapat menjaga pola makan $3 \mathrm{~J}$ (Jadwal, Jumlah dan Jenis).

Edukasi kesehatan adalah proses untuk meningkatkan kemampuan masyarakat dalam memelihara dan meningkatkan kesehatan. Sedangkan dalam keperawatan pendidikan kesehatan merupakan suatu bentuk intervensi keperawatan yang mandiri untuk mambantu klien baik individu, kelompok, maupun masyarakat dalam mengatasi masalah kesehatannya melalui kegiatan pembelajaran yang didalamnya perawat berperan sebagai perawat pendidik. Pengertian edukasi kesehatan adalah proses membuat orang mampu meningkatkan kontrol dan memperbaiki kesehatan individu. Kesempatan yang direncanakan untuk individu, kelompok atau masyarakat agar belajar tentang kesehatan dan melakukan perubahan-perubahan secara suka rela dalam tingkah laku individu. ${ }^{8}$

Hasil analisa peneliti yang dilakukan di Puskesmas Padurenan RT 002 / RW 10 Bekasi bahwa Pemberian edukasi dapat meningkatkan pengetahuan pasien tentang gaya hidup sehat dan upaya mengontrol kadar

Tabel.7 Pengaruh Sebelum Dan Sesudah Dilakukan Edukasi Kesehatan Diet Diabetes Terhadap Tingkat Pengetahuan Pada Penderita DiabetesMelitus Di Puskesmas Padurenan RT002 / RW10 Bekasi 2019 ( $n=12)$

\begin{tabular}{|c|c|c|c|c|}
\hline & Mean & $T_{\text {Hitung }}$ & $\mathrm{T}_{\text {Tabel }} D f(11)$ & P value \\
\hline Pre Test & & & & \\
\hline Post Test & -5.333 & -14.182 & 2.201 & 0.000 \\
\hline
\end{tabular}

(Sumber : hasil pengolahan data dengan cara komputerisasi Tim Juli 2019)

Tabel 7. menunjukan bahwa dengan menggunakan Uji Paired Sample T-Test diperoleh statistik $p$ value sebesar 0.002 ( $p$ value< 0.05 ), berarti ada pengaruh glukosa darahnya, sedangkan pengetahuan adalah faktor predisposisi terjadinya perilaku, seperti pengetahuan seseorang atau masyarakat tersebut terhadap apa yang akan dilakukan, keyakinan, kepercayaan, nilai-nilai, dan sebagainya.

Hal ini sejalan dengan penelitian yang dilakukan oleh Ayu Putri Rahayu (2012) diketahui bahwa hasil statistik membuktikan ada pengaruh edukasi gizi terhadap peningkatan pengetahuan dan perubahan sikap pada pasien DM Tipe 2 dengan nilai $p=$ $0,000<0,05$.

Tabel.6 Uji Normalitas Data Kadar Gula Darah sebelum dan Sesudah Dilakukan Senam Kaki

\begin{tabular}{cccc}
\hline Variabel & Pengukuran & P Value & Frekuensi \\
\hline Kadar & Sebelum & 0,139 & 12 \\
\cline { 2 - 4 } Gula & Sesudah & 0,192 & 12 \\
Darah & & & \\
\hline
\end{tabular}

(Sumber : hasil pengolahan data dengan cara komputerisasi Tim, Juli 2019)

Hasil uji normalitas dengan menggunakan analisa uji shoper wilk dengan jumlah sampel 12 responden $(n=12)$ pada tingkat kemaknaan 95\% (alpha 0,05) sebelum dilakukan senam kaki di dapatkan $p$ value 0,139 setelah dilakukan senam kaki di peroleh $p$ value 0,192 . $P$ value sebelum dan sesudah dilakukan senam kaki dengan hasil kadar gula darah lebih besar dari pada nilai alpha yaitu 0,05

Tabel.8 Pengaruh Sebelum Dan Sesudah Dilakukan Senam Kaki Terhadap Kadar Gula Darah Pada Penderita DiabetesMelitus Di Puskesmas Padurenan RT002 / RW10 Bekasi 2019 ( $n=12$ ) 


\begin{tabular}{lccccc}
\hline & $\mathrm{N}$ & Mean & $\mathrm{T}_{\text {Hitung }}$ & $\mathrm{T}_{\text {Tabel }} D f(11)$ & Sig (2- tailed) \\
\hline Pre Test & 12 & & & & \\
& & 27.583 & 4.006 & 2.201 & 0.002 \\
Post Test & 12 & & & & \\
hasil pengolahan data dengan cara komputerisasi Mila Nofiana, Juli 2019)
\end{tabular}

Tabel 8. menunjukan bahwa dengan menggunakan Uji Paired Sample T-Test diperoleh statistik $p$ value sebesar 0.000 ( $p$ value< 0.05 ), berarti ada pengaruh yang signifikan pengukuran data pre test dan post test. Selisih Mean antara data pre test dan post test sebesar -.5.333.

Berdasarkan hasil penelitian yang dilakukan pada 12 responden, menunjukan bahwa nilai mean tingkat pengetahuan sebelum diberikan edukasi diet Diabetes pada penderita DiabetesMelitus adalah 12.08 dengan standar deviasi 2.875 mengalami kenaikan nilai mean sesudah dilakukan edukasi diet Diabetesadalah 17.42 dengan standar deviasi 2.875.Dalam penelitian ini terdapat perbedaan nilai mean sebelum dan sesudah dilakukan edukasi kesehatan dengan selisih 5.83dapat diartikan bahwa ada pengaruh sebelum dan sesudah dilakukan edukasi kesehatan hasil analisa dengan menggunakan paired sampel $t$ test dengan hasil $p$ value sebesar $(0.000)$ sehingga $p$ value $(0.000)<$ alpha $(0,05)$. Dapat disimpulkan bahwa hasi uji hipotesis dinyatakan $\mathrm{H}_{0}$ ditolak, maka ada pengaruh setelah dilakukan edukasi kesehatan tentang diet Diabetes.

Metode edukasi kesehatan yang digunakan dalam penelitian ini adalah metode edukasi kelompok dengan bentuk ceramah.Media edukasi kesehatan yang digunakan adalah lembar balik dan leaflet. Tujuan memberikan edukasi kesehatan adalah penerapan pendidikan di dalam bidang kesehatan untuk memberikan atau meningkatkan pengetahuan, sikap, dan praktek baik individu, kelompok atau masyarakat dalam memelihara dan meningkatkan kesehatan mereka sendiri,

\section{SIMPULAN DAN SARAN}

Tingkat pengetahuan tentang diet Diabetes sebelum dilakukan edukasi kesehatan pada penderita Diabetes Melitus di Puskesmas Padurenan RT 002 / RW10 Bekasi 2019 dari 12 responden terdapat 4 responden $(33.3 \%)$ berada dalam kategori cukup, dan 8 responden $(66,7 \%)$ berada dalam kategori kurang khusunya bagi penderita DiabetesMelitus agar dapat menjaga pola makan $3 \mathrm{~J}$ (Jadwal, Jumlah dan Jenis).

Edukasi kesehatan adalah proses untuk meningkatkan kemampuan masyarakat dalam memelihara dan meningkatkan kesehatan. Sedangkan dalam keperawatan pendidikan kesehatan merupakan suatu bentuk intervensi keperawatan yang mandiri untuk mambantu klien baik individu, kelompok, maupun masyarakat dalam mengatasi masalah kesehatannya melalui kegiatan pembelajaran yang didalamnya perawat berperan sebagai perawat pendidik. Pengertian edukasi kesehatan adalah proses membuat orang mampu meningkatkan kontrol dan memperbaiki kesehatan individu. Kesempatan yang direncanakan untuk individu, kelompok atau masyarakat agar belajar tentang kesehatan dan melakukan perubahan-perubahan secara suka rela dalam tingkah laku individu. ${ }^{8}$

Hasil analisa peneliti yang dilakukan di Puskesmas Padurenan RT 002 / RW 10 Bekasi bahwa Pemberian edukasi dapat meningkatkan pengetahuan pasien tentang gaya hidup sehat dan upaya mengontrol kadar glukosa darahnya, sedangkan pengetahuan adalah faktor predisposisi terjadinya perilaku, seperti pengetahuan seseorang atau masyarakat tersebut terhadap apa yang akan dilakukan, keyakinan, kepercayaan, nilai-nilai, dan sebagainya.

Hal ini sejalan dengan penelitian yang dilakukan oleh Ayu Putri Rahayu (2012) diketahui bahwa hasil statistik membuktikan ada pengaruh edukasi gizi terhadap peningkatan pengetahuan dan perubahan sikap pada pasien DM Tipe 2 dengan nilai $p=$ $0,000<0,05$.

1. Tingkat pengetahuan tentang diet Diabetes sesudah dilakukan edukasi kesehatan pada penderita DiabetesMelitus di Puskesmas Padurenan RT002 / RW10 Bekasi 2019 dari 12 responden terdapat 4 responden $(33,3 \%)$ berada dalam kategori baik, dan 8 responden $(66,7 \%)$ berada dalem kategori cukup. 
2. Kadar gula darah sebelum diberikan senam kaki pada penderita Diabetes Melitus di Puskesmas Padurenan RT002 / RW10 Bekasi 2019 dari 12 responden terdapat 7 responden $(58,3 \%)$ berada dalam kategori tinggi dan 5 responden $(41,7 \%)$ berada dalam kategori sangat tinggi

3. Kadar gula darah sesudah diberikan senam kaki pada penderita DiabetesMelitus di Puskesmas Padurenan RT002 / RW10 Bekasi 2019 dari 12 responden (100\%) berada dalam kategori tinggi

4. Terdapat perbedaan tingkat pengetahuan sebelum dan sesudah diberikan edukasi kesehatan pada penderita Diabetes Melitus di Puskesmas Padurenan Bekasi, dengan $P$ value sebesar 0,000 ( $p$ value $<$ 0.05 ). berarti ada perbedaan yang menunjukan pengukuran dara pre test dan post test. Selisih mean antara data pre test dan post test sebesar -5.333.

Terdapat perbedaan kadar gula darah sebelum dan sesudah diberikan edukasi kesehatan pada penderita Diabetes Melitus di Puskesmas Padurenan Bekasi, dengan $P$ value sebesar 0,002 ( $p$ value $<$ 0.05 ). berarti ada perbedaan yang menunjukan pengukuran dara pre test dan post test. Selisih mean antara data pre test dan post test sebesar 27.583

5. Saran Bagi Peneliti Selanjutnya dan Perkembangan Riset Keperawatannya peneliti selanjutnya mampu menggali lebih dalam lagi hal - hal yang dapat meningkatkan pengetahuan tentang diet diabetes, dan yang dapat menurunkan kadar gula darah dalam batas normal,

\section{DAFTAR PUSTAKA}

[1]. Bilous Rudy, R. D. (2015). Buku Pegangan Diabetes. (Barrarah Bariid, Ed.) (Edisi 4). Jakarta: Bumu Medika. .( Daftar pustaka dari buku)

[2]. Dharma Kelana Kusuma. (2015). Metodologi Penelitian Keperawatan (Pedoman Melaksanakan Dan Menerapkan Hasil). Jakarta Timur: Trans Info Media. .( Daftar pustaka dari buku)

[3]. Murwani Arita. (2014). Pendidikan Kesehatan Dalam Keperawatan. Yogyakarta: Penerbit Fitramaya. .( Daftar pustaka dari buku)

[4]. Novi Ayuwardani1. (2018). Pengaruh Pola Makan Terhadap Kadar Malondialdehid Plasma Sebagai Upaya Pencegahan
Diabetes Mellitus Di Usia Remaja. Keperawatan. .( Daftar pustaka dari Jurnal)

[5]. Pranata Satriya, D. U. K. (2017). Merawat Penderita Diabetes Melitus (Edisi 1). Yogyakarta: Pustaka Panasea. .( Daftar pustaka dari buku)

[6]. Rita Fitri Yulita. (2019). Pengaruh Senam Kaki Terhadap Penurunan Skor Neuropati Dan Kadar Gula Darah Pada Pasien Dm Tipe 2. Journal Of Telenursing, 1. . ( Daftar pustaka dari Jurnal)

[7]. Setiadi. (2016). Konsep Dan Praktik Penulisan Riset Keperawatan (Edisi 2). Yogyakarta: Graha Ilmu. .( Daftar pustaka dari buku)

[8]. Setyoadi. (2018). Diabetic, Influence Of Nutrition Education With Calendar Method In Glucose, Patients' Blood. Nurseline, 3. .( Daftar pustaka dari Jurnal)

[9]. Tandar Hans. (2018). Segala Sesuatu Harus Anda Ketahui Tentang Diabetes (Edisi 2). Jakarta: Pt Gramedia Pustaka Utama. .( Daftar pustaka dari buku)

[10]. Dyah Restuning P. (2015). Efektifitas Edukasi Diabetes Dalam Meningkatkan Kepatuhan Pengaturan Diet Pada Diabetes Melitus Tipe 2, 15. .) Daftar pustaka dari Jurnal)

[11]. Ridha Hidayat. (2017). Pengaruh Senam Terhadap Kadar Gula Darah Pada Penderita Diabetes Mellitus Tipe 2 Di Rsud Puri Husada Tembilahan Tahun 2016, 1. . ( Daftar pustaka dari Jurnal) 